\title{
When Methods Meet Motives: methodological pluralism in Social Work research
}

\author{
Martine Ganzevles ${ }^{1,2}$ (D) Daan Andriessen ${ }^{1} \cdot$ Tine Van Regenmortel $^{2,3}$. \\ Jaap van Weeghel W,5 $^{4,5}$
}

Accepted: 3 May 2021 / Published online: 13 May 2021

(C) The Author(s) 2021

\begin{abstract}
In Social Work research there is a strong debate on the distinctiveness and methodological quality, and how to address the dilemma of rigour and practice relevance. Given the nature of Social Work the field has developed a characteristic research culture that puts emphasis on giving voice to service users and disseminating research knowledge in practice, especially in a stream of so called practice-based research. However, there is no consensus on how to best contribute to the practice of Social Work through research and at the same time producing rigourous scientific outcomes, resulting in methodological pluralism. Studying the perceptions of Social Work researchers on their role, the aims and values of Social Work research and their research approach, provides insight into the methodological pluralism of Social Work research. Thirty-four professors specialising in practice-based Social Work research participated in a Q methodology study. Q methodology combines qualitative and quantitative methods. It helped reveal and describe divergent views as well as consensus. The analysis led to the identification of three differing viewpoints on Social Work research, which have been given the following denominators: The Substantiator, The Change Agent and The Enlightener. The viewpoints provide researchers in the field of Social Work with a framework in which they can position themselves in the methodological pluralism. Researchers state that the viewpoints are helpful in clarifying perspectives on good research, facilitate the discourse on methodological choices to further develop and strengthen Social Work research as a scientific discipline.
\end{abstract}

Keywords Practice-based research · Q methodology · Research approaches · Social Work research $\cdot$ Methodological pluralism

\section{Introduction}

In Social Work research, different theoretical, methodological and empirical approaches interplay with different perceptions of Social Work (Engen et al. 2019). This raises questions about the issue of knowledge of and for Social Work, and about the means and the

Martine Ganzevles

martine.ganzevles@hu.nl

Extended author information available on the last page of the article 
methods by which this should be obtained (Hothersall 2019). The answers to these questions lead to different positions and approaches, occupied by different researchers and include approaches to give voice to service users, to facilitate collaboration between practice and research, and cope with ethical issues of doing research in close relation with practice.

A description of Social Work research cannot be understood in a clear definition or identified on a type of method, but much more in terms of what purpose it serves (Shaw 2018). As a field of research, social work is concerned with understanding the problems that vulnerable individuals experience and in assessing the impact of social policies and professional interventions whose goal is to improve the situation (Ellingsen 2010). Social Work research takes shape in (post-)positivism, constructivism and critical realism (Driessens et al. 2015). It is therefore not possible nor desirable to address the research with one paradigm. As an example the European Social Work Research Association (ESWRA) states as the objective to take forward the development, practice and utilization of Social Work research to enhance knowledge about individual and social problems, and to promote just and equitable societies. Besides the purposes served, it also states about the various ways to achieve these goals: "providing an environment for the application of research methods and approaches by those from a wide range of disciplines within and beyond the social sciences, in forms which have relevance for Social Work practice and research" (https://www. eswra.org/about.php).

The different positions are all part of the debate on the distinctiveness and methodological quality of Social Work research (Shaw 2007), and how to address rigour and practice relevance. Social Work researchers appear to differ in terms of what constitutes good Social Work research, and what are the best fitting ways in which research can serve practice, including ethical considerations. However, in this debate about the close relationship between Social Work research and practice, little attention is given to differences in the role conceptions and motives of Social Work researchers. While some researchers may feel comfortable to adopt a participative role in practice, others may be more inclined to opt for a more distant role. Various positions in this concourse determine how Social Work researchers approach the challenges of Social Work research and the choices they make regarding their research approach.

The issues in dealing with diversity of interests, controversies, conflicts, barriers and dilemmas in Social Work research (Engen et al. 2019) are perhaps most prominent for researchers whose goal is to contribute both to practice and to science. How do the topics in the debate work out for researchers who claim to conduct practice-based research? How do practice-based researchers handle these issues and how does this affect their research approach? Practice-based research seeks to define practice-based knowledge through shared understandings and is not reflected in a single philosophy or methodology (Julkunen 2015). Practice-based research we therefore define as scientific research, in which questions derived from practice are central, and is aimed at supporting, improving, and transforming practice as well as contributing to professionalization and scientific underpinning of Social Work (Andriessen 2014; Metz 2017). The aim of the study presented is to gain insight into the perceptions of practice-based Social Work researchers and into what is decisive in their research approach. This insight contributes to the discourse among Social Work practicebased researchers about what constitutes good Social Work research to further develop and strengthen Social Work research as a scientific discipline. The perceptions, including motives; reasons that causes a person to act in a certain way, influence inner- and outer science considerations (Shaw and Norton 2007), research methodology and practice concerns (Teater et al. 2018). 
In this study Q methodology was used to systematically analyse this subjective matter. Q methodology allows for the sampling of subjective viewpoints and can assist in identifying patterns, including areas of difference or overlap, across various perspectives on a given phenomenon (Watts and Stenner 2012; Brown et al. 2015). The viewpoints of the thirty-four participants in this study, except for one associate professor, all of them full professor of practice-based Social Work research at Dutch universities of applied sciences, are relevant to the complex subject of study, namely motives underlying the chosen strategies for practice-based Social Work research.

\section{Research method: the application of the five steps of $Q$ methodology}

Q methodology was developed by William Stephenson (1953) as a means of gaining access to subjective viewpoints. To study viewpoints such as personal experiences, matters of taste, values and beliefs, Q methodology combines qualitative and quantitative methods (Baker et al. 2006; Jedeloo and Van Staa 2009; Van Exel and De Graaf 2005, 2015). This combination of methods and the specific purpose of studying subjectivity was the reason for choosing Q methodology to capture the perspectives as intended with this study. Participants in a Q-study are asked to rank order a set of statements on the topic at hand on a grid and clarify their ranking in a post-sorting interview.

Two main features are characteristic for Q methodology studies: the collection of data in the form of Q-sorts and the subsequent intercorrelation and by-person factor analysis of these Q-sorts. In line with these two features each Q methodological study is carried out according to the following five steps; (1) establishing the concourse on the given topic, (2) developing the so-called Q-set: the concourse comprised in a workable set of statements, (3) selection of the P-set, the participants in the study (4) the Q-sorting by the participants, and (5) Q-analysis and interpretation (Brown 1980; Van Exel and De Graaf 2005, 2015; Watts and Stenner 2012).

The following paragraphs outline the five steps of this Q-study, explaining what each step entailed, how it was designed in this study and how we worked on quality criteria.

\subsection{Establishing the concourse resulting in the Q-set (step 1 and step 2)}

The set of statements the participants are asked to rank in a Q-study represent the essence of what a participant could say on the subject, and is called the Q-set (Van Exel and De Graaf 2015). As the concourse, the essence of the subject is established, it becomes the pool of opinions from which the Q-set statements are drawn (Kenward 2018). The concourse refers to 'the flow of communicability surrounding any topic' (Brown 1993).

The concourse in this study was established by mapping out the current discussion on what is decisive in establishing a research approach as represented in several sources. First, we explored theoretical sources such as research literature and general theories on social science. This theoretical exploration led to general notions on conducting scientific research such as validity, generalisability and transferability.

As a second source, we studied the sequential statements on Social Work Practice Research (Austin and Uggerhøj 2014; Salisbury Forum Group 2011; Sim et al. 2019) which led to supplementary information concerning collaboration with and participation of professionals and service users. 
Concurrent with this theoretical exploration, the Rathenau Institute conducted a survey among researchers at Dutch research universities and universities of applied sciences (Koens et al. 2018). The purpose of this survey was to identify the motives behind the researchers' work. Therefore, it was a useful third source in building the concourse for our study. It provided additional notions on the intended outcome of research projects, on publishing and on preconditional notions such as financing opportunities.

A fourth source for building the concourse consisted of two focus groups (McKeown and Thomas 2013) we organised for this study. One international focus group was formed by the participants of the special interest group (SIG) Social Work Practice Research at the annual European Conference Social Work Research (ECSWR) in Aalborg in 2017. The second focus group consisted of Dutch researchers from different disciplines at a research conference in May 2017. Members of the two focus groups were invited to expound on what is decisive in their research approach. Participation in the focus groups was voluntary after an explanation of the purpose and use of the data was given and questions could be asked. Consulting the Ethics Review Board of Tilburg University confirmed that there are no ethical concerns (EC-2018.EX192). Data was not collected or retraceable on a personal level and participants could leave whenever they desired. These focus groups contributed to building a comprehensive concourse with elements concerning practical applicability, wishes and needs in practice-based research and the researcher's position in practice.

Once the concourse was established, statements could be distilled for the Q-set. The preliminary versions of the Q-set were tested on face-, construct- and content-validity (Paige and Morin 2016). Two different groups of researchers were asked to perform a Q-sort and to report everything prominent, such as missing elements, the language used, inconsistencies and possible duplications in order to consider the coverage, clarity and heterogeneity of the statements. The members of one group $(n=7)$ specialised in research methodology, members of the other $(n=9)$ in Social Work research.

The final set of 37 statements in this balanced Q-set (see Tab. 2) can be subdivided in four key types of considerations (1) methodological rigour, (2) practical relevance, (3) normative elements and (4) preconditional elements. A statement can encompass one or more considerations.

This set was piloted with two representatives of the envisaged group, both full professor Social Work. This pilot resulted in minimal changes to the phrasing of the statements. In addition, the pilot gave the researcher insight on how instructions could best be given and how to facilitate the sorting, for example how to position yourself relative to the participant and the grid.

\subsection{Participants: the P-set (step 3)}

The number of participants in a Q-study, in Q-terminology the $P$-set, can vary. The quality of the set of participants is of more importance than the quantity (Van Exel and De Graaf 2015) and saturation of the interview content is the criterion. In practice, many studies are based on 30 to 40 interviews (Van Exel and De Graaf 2015; Watts and Stenner 2012). The 34 participants in this study were chosen by purposive sampling $(n=21)$ and additional snowball sampling $(n=13)$. The purposive sampling was based on a previous study conducted by the authors. In that study a sample of 311 publications on Social Work research by Dutch universities of applied sciences were coded on their methodological variables (Ganzevles et al. 2020). Outliers in this study, i.e. outliers in a conducted principal component analysis, led to 21 participants: the leading researcher of the respective project 


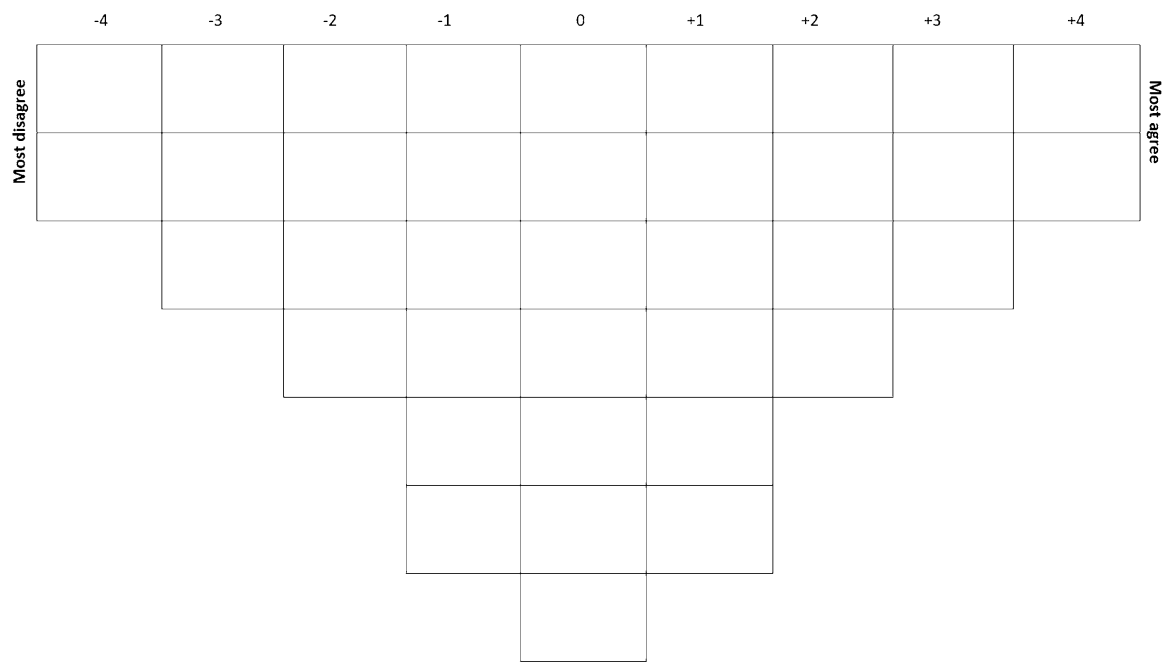

Fig. 1 Pre-structured sorting grid used in this study

published. The outliers were chosen because we seek the broadest possible range of opinions. These participants were asked in the post-sort interviews who they thought should also be included and for what reason. This additional selecting method of snowball sampling resulted in another thirteen participants.

The thirty-four participants were approached by email, and all agreed to participate and gave informed consent. The participants all professor of Social Work at Dutch universities of applied sciences, of which twenty are female and fourteen male. The average age is 52 years [36-65 years]. Work experience as a researcher at a university of applied science showed a spread of two to seventeen years, with an average of ten years.

\subsection{Administering the Q-sort and post-sort interview (step 4)}

Administering the Q-sort consists of three stages (Brown 1980). First, the participant reads all the statements and divides them in three piles: agree, not agree and neutral. As a second step, the participant ranks the statement in a pre-structured grid. The third and final step is an interview after the ranking is completed to be able to discover the individual rationale for the ranking, in order to interpret and describe the similarities and differences after analysis (Gallagher and Porock 2010).

After a short introduction on the objective and purpose of the study, and roughly sorting the set of statements into the three piles, the participants rank ordered the set along a pre-structured and symmetrical grid. As we expected the participants to have articulated opinions on the topic at hand, the kurtosis of the forced distribution is somewhat flat in order to compel for strong (dis)agreement with statements (Van Exel and De Graaf 2005). This consideration has led to a grid with a spreading ranging from +4 : Most agree, to -4 : Most disagree (see Fig. 1).

Ranking of the items is relative to one another, i.e. that ranking in the middle is not indicative of neutrality, and there is no limit to the number of items that can be placed in a category. In theory, it is possible a participant ranks all items as 'agree with' or 'disagree with'. Some discrimination, just agreeing slightly less or more than the item ranked 
immediately above or below, will take place by ranking them in the grid (Watts and Stenner 2012: p. 84). After positioning all statements, participants reviewed their whole set for a final check and could still rearrange the cards if they thought this was necessary. In the end, it had to be a comfortable set for the participant for that moment.

In a post-sort interview, the researcher invited the participants to elaborate on their underlying reasons and ideas about the particular placement of the statements. The placements on the far right and left, the statements the participant agreed or disagreed with the most, served as the starting point of the interview. After explaining the outer placings, participants went into detail on what other statements are decisive in their research approach or described the practical application of a statement.

Participants also had the opportunity to indicate what was unclear or what in their opinion was missing. When they stated that something was unclear, they could give their own interpretation of the positioning in their sort. There were very few additions and most of the additions concerned specifications of a given statement. The post-sort interviews provided meaning and a rich narrative description (Gallagher and Porock 2010).

As a last task, the participants answered three questions in writing. They wrote down: (1) relevant demographic data, (2) what they consider as relevant own lived experience for their research function, e.g. education, work and personal experience, and (3) a brief stance on what is decisive when making methodological choices in their Social Work research design.

Logging of the data was done by sound recording the entire session and by taking a photo of the Q-sort and copying it in a digital document. The written answers were scanned and copied in a digital document.

\subsection{Statistical and qualitative analysis (step 5)}

With Q methodology it is possible to look for similar patterns of Q-sorts between participants, with the expectation that participants with similar rankings would share similar viewpoints (Jedeloo and Van Staa 2009). To establish such insight in patterns a by-person factor analysis was used, and not as in contrast with other common research a by-item factor analysis which clusters the statements. This Q-study yielded, besides rich encounters, a large set of data. Analysis and interpretation demanded a highly sensitive approach in a process that involved going back and forth between the quantitative and the qualitative data.

Sorting data were subjected to centroid factor analysis and varimax factor rotation with PQMethod release 2.35 (Schmolck 2014). This by-person factor analysis and factor rotation resulted in groupings of respondents who share similar perspectives. We followed the golden rule in Q methodology starting the analysis with seven factors and checking for explained variance and factor loadings. After peer-debriefing the three-factor solution was agreed in order to best represent the data and offers the highest explanatory power. For each factor the idealised score was calculated for every single statement.

The sound recordings of the post-sort interviews were fully transcribed and coded in Atlas.ti 8 for Windows. This qualitative information underpinned the holistic factor interpretation. As we were interested in a full explanation of the whole viewpoint, it demanded 'to keep sight on the fundamentally holistic character of the factor arrays'(Watts and Stenner 2012: p. 149) and to look more broadly than merely on the four items ranked highest and lowest. This generated a sense of the overall story being told by the various item rankings, 'working on the main aim of factor interpretation; making sense of the wood' (Watts 
Table 1 Characteristics of the 3 -factor solution

\begin{tabular}{lllll}
\hline & I & II & III & Total \\
\hline Factor & & & & \\
Amount of defining variables & 12 & 11 & 6 & 29 \\
Explained Variance & 17 & 20 & 11 & 48 \\
\hline & I & II & III & \\
\hline Correlations between factor scores & & & & 0.6245 \\
I & 1 & 0.4527 & 0.5024 & \\
II & 0.4527 & 1 & 1 & \\
III & 0.6245 & 0.5024 & &
\end{tabular}

and Stenner 2012: p. 156). When a statement emerged as consensus in the factor analysis, the interview data were gathered from the transcripts and used to facilitate understanding of this statement. It pointed out the statements that made the most profound contributions within the factor arrays. By working through all the items and considering their relevance in the context of the overall viewpoint, a full factor interpretation was possible, and a story emerged for each viewpoint. The factors are in that way described while retaining a sense of humanity (Watts and Stenner 2012).

\section{Results}

The analysis of the extensive data collection, both statistical and qualitative, resulted in three main views. These are described in this chapter, and the Q methodology is assessed in conclusion.

\subsection{Three viewpoints}

The analysis led to the identification of two distinctive trends, and partial support for a third. The three viewpoints together have an explained variance of $48 \%$. Of the 34 participant 29 load on one of the factors (see Table 1). Each factor has an Eigen Value above one and therefore meets the Kaiser Guttman Kriterion (Kaiser 1970; Watts and Stenner 2012).

After establishing the three viewpoints, we presented them with the full factor interpretations in multiple groups as a member check, e.g. the international SIG meeting Social Work Practice Research at ECSWR, and the annual conference of Dutch Social Work knowledge centres. The results were presented using a triangle where each angle represented a view, making it clear that no one is likely to fully coincide with one viewpoint. Researchers were asked to position themselves in the triangle and to explain their position and how this position is reflected in their work. Comments given by those groups helped to tie up loose ends.

Table 2 contains the factor arrays for this factor solution. The factor array provides the grid position for each Q-sample item for each factor. Thus, each factor array represents the theoretical sort for that viewpoint. 


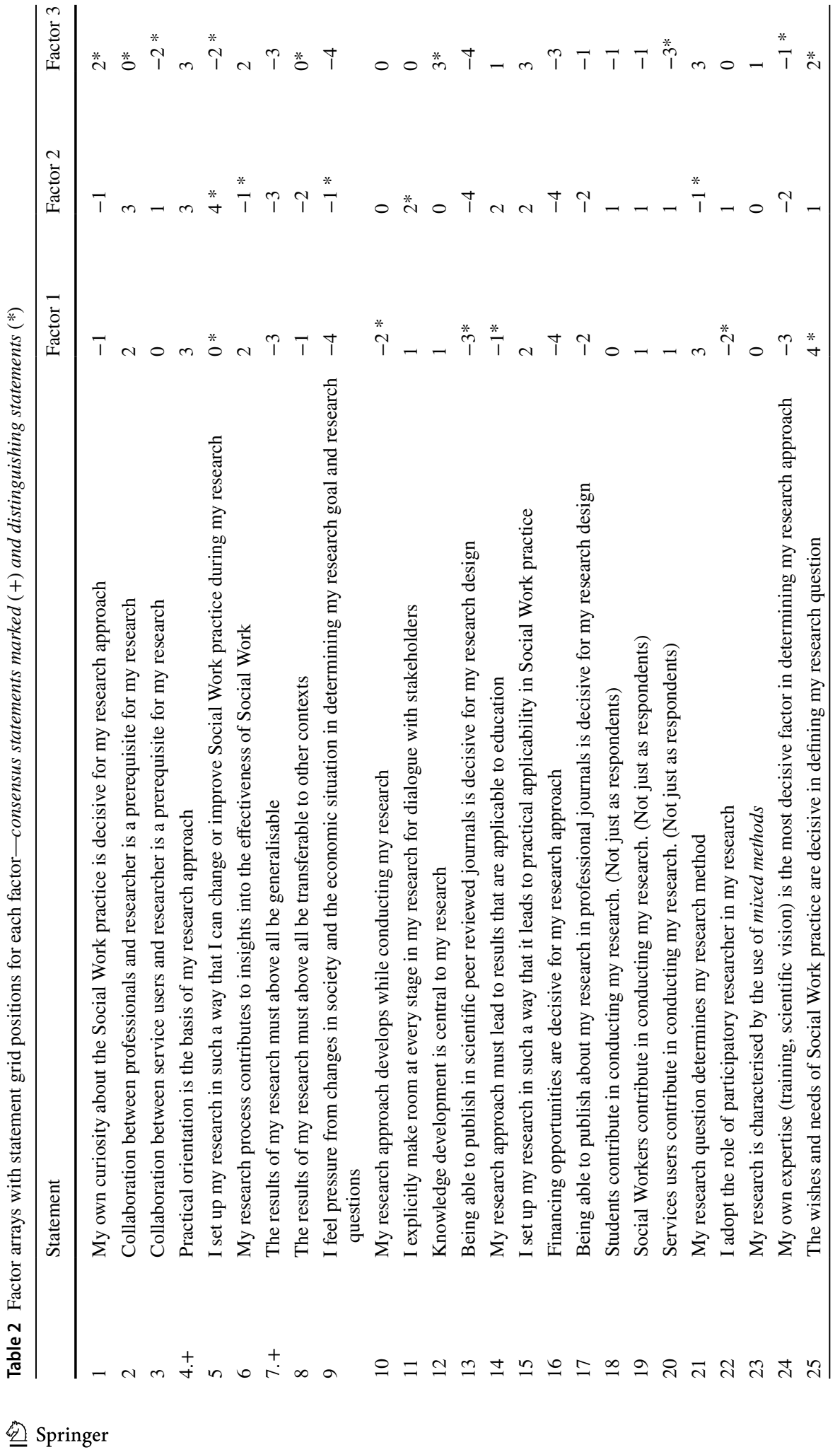




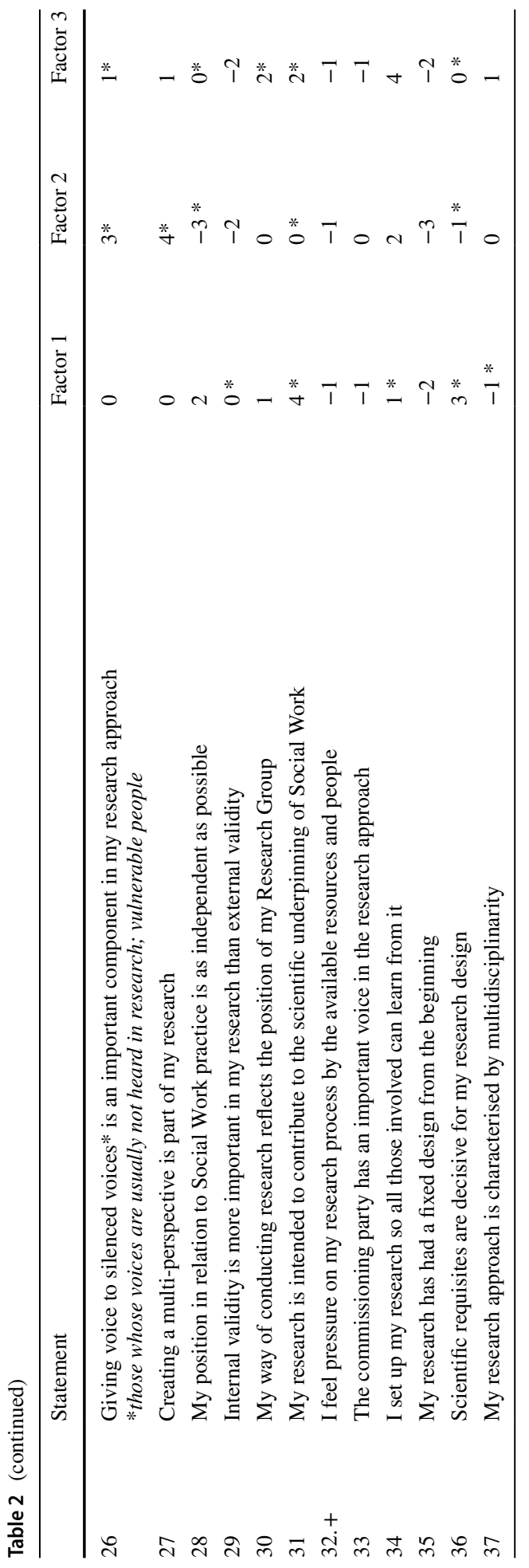




\subsubsection{Factor 1: The Substantiator}

Practice-based research should follow the basic requirements of science and outcomes should provide a foundation for practice (to prove). The research question stems from practice, but research is a job for experts.

On this first distinguishing factor, 12 out of 34 participants load significantly, and account for an explained variance of $17 \%$. Contributing to the scientific underpinning of Social Work is seen from this viewpoint as the main goal of research $(31:+4) .{ }^{1}$ The questions and needs in practice are the starting point $(25:+4)$. For the scientific underpinning it is important to conduct research according to the common requisites in science $(36:+3)$. Among others, this includes working with predetermined designs as much as possible (35: -2 ) and outcome measures based on theory and literature study. Ensuring the highest possible internal as well as external validity also meets this motive (29: 0). These requirements are considered necessary in order to be able to report on the effectiveness of Social Work, another common motive in this view $(6:+2)$.

The notion that the research question determines the method of research is strongly shared in this viewpoint $(21:+3)$. This notion implies that the researcher's own curiosity $(1:-1)$ or own expertise is not leading $(24:-3)$, but $s /$ he looks for the most suitable design, which can be mixed methods if necessary (23: 0). It also means that the researcher chooses a position which is as independent as possible. This position of independence is described by the participants as follows: they are the expert in the field of research and therefore determine the research approach $(33:+3)$. Independence is explained in more detail by being able to report all findings even if these are not in line with the expectations of commissioning parties.

Publishing in professional $(17:-2)$ or scientific journals (13: -3$)$ is mainly seen as a form of knowledge sharing and not as a goal in itself and therefore does not influence the chosen methodology. When the requirements of science are met, publishing in scientific journals is easily possible, but a research design is not determined by the idea of publishing. The added value of introducing multiple perspectives by focusing on multidisciplinarity (37: -1 ) is seen and applied but not viewed as characteristic of their research. Again, such a perspective is only chosen when it contributes to the desired research outcome.

All those involved can learn from the research, but not necessarily in and through the research $(34:+1)$. Participatory forms of research $(22:-2)$ as well as forms of co-research by Social Workers $(19:+1)$ and service users $(20:+1)$ are therefore less obvious.

Contributing to silenced voices being heard (26: 0 ) and to creating a multi-perspective (27: 0) are recognised as goals of Social Work. Social Work research should therefore certainly not counteract these aims, but are not seen as a necessary part of the research strategy. Collaboration with Social Workers $(2:+2)$, and to a lesser extent with service users (3: $0)$, is seen more as a condition in order to actually be practice-oriented and to do research with outcomes that can be applied in practice $(15:+2)$. After all, they want to connect with the questions and needs of practice and take an independent position on this. Themes on the agenda have practical orientation in mind $(4:+3)$, which makes social developments urgent.

$\overline{1}(31:+4)=$ first digit referring to the statement number, second digit the theoretical sort in the viewpoint. 


\subsubsection{Factor 2: The Change Agent}

Practice-based research is a joint process between research and practice in which practice can change during the course of the research (to improve). Stakeholders have their own expertise and therefore have an important role.

On this factor, 11 of 34 participants load significantly. This factor has an explained variance of $20 \%$. Researchers with this viewpoint regard research as a possibility for gradually changing practice $(5:+4)$. Creating a multi-perspective is an explicit part of their research approach $(27:+4)$. To bring about change as the research progresses, cooperation between the researcher, professionals $(2:+3)$ and service users is a prerequisite $(3:+1)$. Establishing a dialogue between stakeholders is deliberately incorporated in the research design $(11:+2)$. The position of the researcher is often in a participatory role $(22:+1)$ in which independence from practice is considered impossible (28: -3$)$. This does not alter the fact that it should be possible to report on all findings. The researchers' own curiosity for practice is high and seen as a drive for the personal involvement of the researcher. However, this is not decisive for the research approach $(1:-1)$.

Designing the research is done in consultation with the commissioning party (33: 0). Often research is conducted in consortia or project structures without strict division of roles between the commissioning party and the contractor/researcher. From the early stages of the research, establishing the research question, silenced voices are explicitly taken into account $(26 ;+3)$. These voices are heard not only in the role of respondent, but also in the role of co-researcher for both the service user $(20:+1)$ and the Social Worker $(19:+1)$. Since the research is conducted in and with the often-unruly practice, the research approach may develop during the course of the research (10:0); hence the approach is not fixed from the start $(35:-3)$.

Scientific underpinning is seen as desirable for Social Work. In this view, underpinning is mainly based on practical orientation $(4:+3)$ and with the intent that results can be applied in education $(14:+2)$. Participants use other terminology in describing how research should contribute to a scientific underpinning of Social Work: not primarily from theory-driven research, but practically underpinned by practice-based research. Effect studies are therefore hardly ever conducted (6: -1$)$, nor is research with the primary aim of knowledge development (12: 0). Research is seen as a means that should lead to practical applicability $(15:+2)$; it is seen as a motor for innovation and change. This can be done using mixed methods (23: 0). Mixed methods is interpreted more broadly than the usual definition of purely qualitative and quantitative research, namely also mixed in the sense of arts-based research, design research and action research.

Publishing research results in professional journals is seen as appropriate for practice-based researchers, publishing in scientific journals to a lesser extent as it does not substantially contribute to the objectives. In either case, being able to publish in any type of journal does not determine the research design (13: -4 and 17: -2 ).

In the determination of the research question a certain pressure is experienced due to social developments $(9:-1)$. The research question is established in dialogue, just as it will be answered (33: 0). The question therefore determines the method only to a certain extent $(21:-1)$; as practical change is an important motive, an appropriate type of research is obvious. Scientific requirements $(36:-1)$ are met with practical orientation in mind (4:3) and mainly concern aspects of trustworthiness such as confirmability and transparency. Generalisability $(7:-3)$ and transferability $(8:-2)$ of results are not pursued as the highest good. 
Funding plays a role since no research can be done without money, but there is no pressure felt to choose the research approach due to funding opportunities (16: -4). Doubts are expressed about whether certain calls articulate the actual practice questions and, in addition, whether the proposed methods to answer these questions are the most appropriate to obtain usable results.

\subsubsection{Factor 3: The Enlightener}

The researcher's own curiosity about practice is the starting point of the research. The researcher is the expert and wants to teach and tell practice with research. The researcher's expertise is used for the benefit of knowledge sharing in which all parties involved can learn.

Of the 34 participants, six load significantly on this factor. This factor has an explained variance of $11 \%$. The fact that all those involved can learn from the research $(34:+4)$ is seen as the most important motive when designing their research, therefore knowledge development is the central aim $(12:+4)$. Practitioners must be able to find knowledge obtained from research, which is why publishing in professional journals is seen as more important $(17:-2)$ than in scientific journals (13: -4). Consequently, possibilities for publication do not have a role in the research design. However, the researcher's own curiosity $(1:+2)$ does have a pivotal role and is the starting point of the research. Participants state they know practice well and know what is needed. Therefore, the research question does not have to emerge explicitly from practice $(25:-1)$. A self-identified issue, a personal interest or enthusiasm for a theme is then the basis for the research question, hence the name of this factor: The Enlightener.

Participants do not experience any pressure on determining their research aim and questions due to changes in society and the economic situation (9: -4$)$. They determine the goal and the questions themselves; as their research starts in practice $(4:+3)$ changes in society are naturally taken into account. Funding opportunities do not lead the research approach (16: -3$)$, and are even seen to contradict their own curiosity.

Contributing to understanding effectiveness, translated as contributing to working more effectively and achieving a better understanding of the perceived benefits of Social Work, is an important motive $(6:+2)$. By increasing knowledge about a target group or by facilitating discussion about what Social Work should achieve, contributing to greater effectiveness is an aim. Research on effectiveness is not defined as researching interventions with randomised controlled trials. This method of effect study is not seen as the most appropriate in the social domain. Rather, the focus is on research with results that are practically applicable $(15:+2)$, choosing research methods in which the results are also transferable (8: 0$)$. When it comes to internal and external validity (29: -2$)$, the proposition is that above all justice should be done to the complex context of practice in which the research was conducted. In this respect, it is considered logical that the chosen methods of research are determined by the research question $(21:+3)$. As a result, the use of mixed methods is also a characteristic of The Enlightener $(23:+1)$, if this is deemed to answer the question.

The participants expect their entire research group to reflect what they stand for $(30:+2)$, and to be congruent in what they say and do. In line with the participant's own curiosity, their personal expertise determines the research approach $(24:-1)$, however, not to the degree that it is the most decisive element. More decisive is the use of insights and theories from other disciplines and collaboration with research groups from other domains, which are both characteristics of multidisciplinarity $(37:+1)$. 
Insights acquired during the research process can lead to a new course of action, therefore the research approach does not have a fixed design (35: -2) and can develop according to the process (10: 0 ). From the same reasoning, practical orientation is of paramount importance (15:3) and a flexible design ensures that it can be adapted to the circumstances in practice. The commissioning party has a say in deciding an approach (33: -1$)$, but as the researcher considers her/himself as the expert, s/he determines the research design in the end. Knowledge development and learning from the outcomes of research is key to this viewpoint; the statements on collaboration with, and contributions by Social Workers (2: 0 and 19: -1$)$ and service users (3: -2 and 20: -3$)$ are therefore less determining. Stakeholder dialogue (11:0) is mainly used in the final phase of research to discuss findings.

\subsection{Consensus statements}

The three viewpoints have three statements ranked in common. The first consensus statement; Practical orientation is the basis of my research approach $(4:+3)$, is in line with expectations since all participants claim to conduct practice-based research. This has often been explained with comments about wanting to conduct research that has practical usefulness and meaning for the target group.

The following two statements turned out to be undifferentiating as well, however towards the 'disagree'-side: The results of my research must above all be generalisable (7: -3), and I feel pressure on my research process by the available resources and people (32: -1). Apparently, generating generalisable knowledge as a research result is not a driver. The post-sorting interviews provide an explanation for this. Most researchers state that since Social Work is context bound, outcomes of the often small-scale research can at best be defined as insights not as evidence (in the positivistic definition). These insights lead to practical knowledge, often on a process level, that can be transferable to other contexts. Several researchers cite this form as exemplary generalisability. The third consensus statement on perceived pressure is recognised, pressure is felt in available resources as well as in people. The latter both quantitatively and qualitatively. The mandatory involvement of lecturers and students is often mentioned. Not only because the educational system often claims them, but also because they are in a learning position when it comes to conducting research. When it concerns available resources, the effort required to apply for grants is perceived as pressure. Almost everyone raises the aspiration for more funding, as ambitions are always greater than what is possible. At the same time, there is also a sense of reality and given the circumstances, they choose the research approach that is most beneficial for practice.

\subsection{Assessing Q methodology}

For most participants it was their first experience with Q methodology. Beside the personal asset, many participants see opportunities for applying this method in their own Social Work research. Possibilities for deploying it with other target groups in Social Work research, such as children or people with learning disabilities using clear sentences or even pictures, were raised. While performing the study the researcher and the participants gained insight into the method itself. Q methodology was received with enthusiasm: 'It really incites you to rethink' and 'almost a game; fun to do!'. Often the participants asserted that the process of ranking the statements encouraged a reflective monologue to articulate their own perspective, and express ideas on motives. This contributes to the 
empowerment of Social Work researchers, as they become more aware of the basic patterns that underlie their actions (Tromp 2005). It affirms that researchers identify with their work (Koens et al. 2018). Often the participants asserted that the statements could be valuable when having conversations on vision and mission within their own research group.

\section{Discussion and implications}

To give insight into the perceptions of practice-based Social Work researchers related to their role conceptions, the aims and values of Social Work and on what is decisive in their research approach a Q methodological study was conducted. The analysis of information provided by the 34 participants led to three distinctive viewpoints: The Substantiator, The Change Agent and The Enlightener.

The most important limitation lies in the fact that the purposive sampling of participants was based on an earlier study by the authors and includes only Dutch Social Work researchers, i.e. professors at Universities of Applied Sciences. As pointed out by Teater et al. (2018) in their comparative study in the UK and USA on building Social Work research capacity the context differs between countries and any similarities and differences between countries other than the one studied should therefore be viewed with caution. The circumstances could give rise to different views. Nevertheless, we think that the core of the three views remains intact. It is quite conceivable that in countries where there are only research universities, more social work researchers will be inclined to contributing to science (Substantiator) than to change (The Change Agent). Notwithstanding the relatively limited sample, this work offers valuable insights into the debate about the complexities and dilemmas in practice-based Social Work research, which also proved to be internationally recognisable. This debate is important in the light of further professionalisation and underpinning of Social Work research. In this debate various viewpoints about what constitutes good practice-based research and how these influences choices in Social Work research designs should be taken into consideration. This study shows that among Social Work researchers with a strong connection with practice different viewpoints exists. Although quality criteria are not in dispute, they are defined differently. The viewpoints can help to explicate and reflect on these differences, and the role perceptions, personal motives and mission. What is often perceived as a theory and practice dichotomy is more of a continuum along the viewpoints: positions in the triangle.

Social Work researchers, including researchers from European countries other than the Netherlands, state that the three viewpoints are recognisable, and it is possible to position themselves in relation to them. Apparently, they transcend local social, political, economic, and social policy conditions. Follow-up research could take a broader international perspective, broader than the European perspective that has now emerged in establishing the concourse for this study.

The viewpoints may appear to differ only marginally in some respects. The asset of Q methodology is the combination of quantitative and qualitative methods, and that strength is demonstrated here. Where the static data showed little difference, delving into the qualitative data revealed that there were actually different motives underneath. The actual confirmation that these are three separate viewpoints was apparent when the views were presented and social work researchers found that the views to be very distinctive, such that they could easily position themselves related to them, and discuss their underlying motives. This supports the ecological validity of the three viewpoints. 
Using the three viewpoints is seen as helpful in clarifying perspectives on vision and mission within own research groups, with fellow Social Work researchers, with practice, commissioning parties and financiers. It makes it clear that different people can have different goals, and different paths lead to those goals. It is as such not a matter of good research, but research with different objectives. In line with Shaw and Norton (2008, p. 953), this study underpins the rationale that in 'terms of assessing quality the Social Work [research] community should not be aiming for precise standards'. We recommend a fitness for purpose and thus embrace pluralism in the pathways leading to those purposes. Social Work is served with the different research purposes as represented in the viewpoints. However, it is desirable that the representatives do not allow themselves to be caught in their positions but enter a critical dialogue with each other, thus strengthening and professionalising Social Work research practice.

Further studies could enhance our understanding on how these views could reinforce each other and support the dialogue towards professionalising and strengthening practicebased Social Work research as a scientific discipline.

Funding The authors received no financial support for the research, authorship, and/or publication of this article.

Code availability PQMethod release 2.35 (Schmolck 2014) and Atlas.ti 8 for Windows.

\section{Declarations}

Conflict of interest The authors report no conflict of interest.

Open Access This article is licensed under a Creative Commons Attribution 4.0 International License, which permits use, sharing, adaptation, distribution and reproduction in any medium or format, as long as you give appropriate credit to the original author(s) and the source, provide a link to the Creative Commons licence, and indicate if changes were made. The images or other third party material in this article are included in the article's Creative Commons licence, unless indicated otherwise in a credit line to the material. If material is not included in the article's Creative Commons licence and your intended use is not permitted by statutory regulation or exceeds the permitted use, you will need to obtain permission directly from the copyright holder. To view a copy of this licence, visit http://creativecommons.org/licenses/by/4.0/.

\section{References}

Andriessen, D.: Praktisch relevant en methodisch grondig; dimensies van onderzoek in het hbo. [Practical Relevance and Methodogical Rigor; Features of Research by UAS] Utrecht: Hogeschool Utrecht (2014)

Austin, M.J., Uggerhøj, L.: Helsinki statement on Social Work practice research. Nordic Soc. Work Res. 56(3), 284-288 (2014)

Baker, R., Thompson, C., Mannion, R.: Q methodology in health economics. J. Health Serv. Res. Policy 11(1), 38-45 (2006)

Brown, S.R.: Political Subjectivity: Applications of Q Methodology in Political Science. Yale University Press (1980)

Brown, S.R.: A primer on Q methodology. Operant Subjectivity 16(3/4), 91-138 (1993)

Brown, S.R., Danielson, S., van Exel, J.: Overly ambitious critics and the Medici Effect: a reply to Kampen and Tamás. Qual. Quant. 49(2), 523-537 (2015)

Driessens, K., Raeymaeckers, P., Sebrechts, L., Tirions, M., \& Wouters, E.: Een caleidoscoop van sociaalwerkonderzoek. Een sociaalwetenschappelijke benadering. Leuven/Den Haag, Acco (2015) 
Ellingsen, I.T., Størksen, I., Stephens, P.: Q methodology in social work research. Int. j. Soc. Res. Methodol. 13(5), 395-409 (2010)

Engen, M., Nissen, M.A., Uggerhøj, L.: Challenges in Social Work research-Conflicts, barriers and possibilities in relation to Social Work. Eur. J. Soc. Work 22(5), 735-737 (2019). https://doi.org/10.1080/ 13691457.2019.1640004

Gallagher, K., Porock, D.: The use of interviews in Q methodology: card content analysis. Nurs. Res. 59(4), 295-300 (2010)

Ganzevles, M., Andriessen, D., Van Beest, W., Van Regenmortel, T., Van Weeghel, J.: The nature of Social Work research by Dutch universities of applied sciences: an overview. J. Soc. Intervention: Theory Pract. 29(1), 41-61 (2020)

Hothersall, S.J.: Epistemology and Social Work: enhancing the integration of theory, practice and research through philosophical pragmatism. Eur. J. Soc. Work. 22(5), 860-870 (2019)

Jedeloo, S., Van Staa, A.: Q-methodologie, een werkelijke mix van kwalitatief en kwantitatief onderzoek? Kwalon, 14(2), 5-15. Retrieved from https://www.tijdschriftkwalon.nl/scripts/shared/artikel_pdf.php? $\mathrm{id}=\mathrm{KW}-14-2-2$ (2009)

Julkunen, I.: Practice-based research: the role of HUSK in knowledge development. J. Evid.-Inform. Soc. Work 12(1), 102-111 (2015)

Kaiser, H.F.: A second generation little jiffy. Psychometrika 35, 401-415 (1970). https://doi.org/10.1007/ BF02291817

Kenward, L.: A literature review to guide novice researchers using Q methodology in the development of a framework for concourse management. Nurse Res. 27(1), 17-21 (2018)

Koens, L., Hofman, R., \& De Jonge, J.: Drijfveren van onderzoekers. Goed onderzoek staat nog steeds voorop. Den Haag (2018)

Metz, J.: Vooraf. In: Platform Lectoren Sociaal Werk. Denken over professionaliteit van het sociaal werk. [Thinking about professionalism of social work] Retrieved from: https://lectorensociaalwerk.nl/publi caties/ (2017)

McKeown, B., \& Thomas, D.B.: Q Methodology (vol. 66):Thousand Oaks: Sage Publications (2013)

Paige, J.B., Morin, K.H.: Q-sample construction: a critical step for a Q-methodological study. West. J. Nurs. Res. 38(1), 96-110 (2016)

Salisbury Forum Group, T.: The Salisbury Statement. Social Work \& Society, 9(1), 4-9. Retrieved from http://www.socwork.net/sws/article/view/2 (2011)

Schmolck, P.: PQMethod. Retrieved from http://www.schmolck.org/qmethod/ (2014)

Shaw, I.F.: Is social work research distinctive? Soc. Work. Educ. 26(7), 659-669 (2007)

Shaw, I., Norton, M.: The kinds and quality of Social Work research in UK universities. Social Care Institute for Excellence, London (2007)

Shaw, I., Norton, M.: Kinds and quality of Social Work research. Br. j. Soc. Work. 38(5), 953-970 (2008)

Sim, T., Austin, M., Abdullah, F., Chan, T.M.S., Chok, M., Ke, C., Julkunen, I.: The Hong Kong Statement on Practice Research 2017: Contexts and Challenges of the Far East. Research on Social Work Practice 29(1), 3-9 (2019)

Stephenson, W.: The Study of Behavior; Q-Technique and Its Methodology. University of Chicago Press, Chicago (1953)

Teater B., Lefevre, M., \& McLaughlin, H. Developing the social work academic workforce: profiles from the United Kingdom and the United States of America. In: Taylor, I., Bogo, M., Lefevre, M., \& Teater, B. (eds.). Routledge International Handbook of Social Work Education. Routledge (2016)

Teater, B., Lefevre, M., McLaughlin, H.: Research activity among UK Social Work academics. J. Soc. Work. 18(1), 85-106 (2018)

Tromp, C.: Breedbeeld wetenschap. [widescreen science\}KWALON. Tijdschrift Voor Kwalitatief Onderzoek in Nederland, 10(1), 7-13 (2005)

Van Exel, J., \& De Graaf, G.: Nieuwsgierig naar meningen of visies? Gebruik Q-methodologie! [Curious about opinions or views? Use Q-methodology!Utrecht: WOSO. Retrieved from PlatformPraktijkontwikkeling.nl (2015)

Van Exel, Job, \& De Graaf, G.: Q Methodology: A Sneak Preview. Job van Exel (2005)

Watts, S., Stenner, P.: Doing Q Methodological Research: Theory, Method \& Interpretation. Sage, London (2012)

Publisher's Note Springer Nature remains neutral with regard to jurisdictional claims in published maps and institutional affiliations. 


\section{Authors and Affiliations}

\section{Martine Ganzevles ${ }^{1,2}$ (D) Daan Andriessen ${ }^{1} \cdot$ Tine Van Regenmortel $^{2,3}$. Jaap van Weeghel ${ }^{4,5}$}

1 Research Group Methodology of Practice-Based Research, HU - University of Applied Sciences Utrecht, PO Box 182, 3500 AD Utrecht, The Netherlands

2 Academic Collaborative Centre Social Work, Tranzo - Tilburg School of Social and Behavioral Sciences, Tilburg University, Tilburg, The Netherlands

3 Faculty of Social Sciences, University of Leuven, HIVA, Leuven, Belgium

4 Academic Collaborative Centre Mental Health Care, Tranzo - Tilburg School of Social and Behavioral Sciences, Tilburg University, Tilburg, The Netherlands

5 Phrenos, Centre of Expertise on the Treatment, Rehabilitation and Recovery of People With Severe Mental Illness in the Netherlands, Utrecht, The Netherlands 